\title{
Megalocornea-intellectual disability syndrome
}

INSERM

\section{Source}

INSERM. (1999). Orphanet: an online rare disease and orphan drug data base.

Megalocornea-intellectual disability syndrome. ORPHA:2479

Megalocornea-intellectual disability syndrome is a rare intellectual disability syndrome most commonly characterized by megalocornea, congenital hypotonia, varying degrees of intellectual disability, psychomotor/developmental delay, seizures, and mild facial dysmorphism (including round face, frontal bossing, antimongoloid slant of the eyes, epicanthal folds, large low set ears, broad nasal base, anteverted nostrils, and long upper lip). Interfamilial and intrafamilial clinical variability has been reported. 